\title{
Incidence of Hepatitis $C$ virus infection in Swat District, Pakistan: a preliminary study
}

Zafran Khan ${ }^{1,2 *}$, Nasib Zaman $^{2}$, Shahid Iqbal ${ }^{2}$, Asaf $\mathrm{Khan}^{3}$, Daniya Ualiyeva $^{1}$, Raja Tahir Mahmood ${ }^{4}$, Gul Rahim ${ }^{5}$, Fazal Akbar ${ }^{2}$ and Ijaz Ali Mian $^{2}$

1. University of Chinese Academy of Sciences, Beijing, 100049, China

2. Center for Biotechnology and Microbiology, University of Swat, Pakistan

3. Department of Microbiology, School of life Sciences, Lanzhou University, China

4. Department of Biotechnology, Mirpur University of Science and Technology (MUST) Mirpur-10250 (AJK),

Pakistan

5. Department of Botany University Malakand (UOM) Chakdara, Dir Lower, Khyber Pakhtunkhwa, Pakistan

*Corresponding author's email: zafrankhan807@yahoo.com

Citation

Zafran Khan, Nasib Zaman, Shahid Iqbal, Asaf Khan, Daniya Ualiyeva, Raja Tahir Mahmood, Gul Rahim, Fazal Akbar and Ijaz Ali Mian. Incidence of Hepatitis C virus infection in Swat District, Pakistan: a preliminary study. Pure and Applied Biology. Vol. 11, Issue 1, pp51-57. http://dx.doi.org/10.19045/bspab.2022.110006

\begin{tabular}{llll}
\hline \hline Received: 12/02/2021 & Revised: 23/04/2021 & Accepted: 29/04/2021 & Online First: 17/05/2021 \\
\hline \hline
\end{tabular}

\section{Abstract}

Hepatitis $\mathrm{C}$ virus (HCV) is the major causative agent for chronic hepatitis $\mathrm{C}$, a global health concern. The epidemiology, pattern of transmission, different genotypes, and clinical consequences of the disease have been studied worldwide, but little is known about the epidemiology of HCV infection in Pakistan and especially about the Swat region. The current study aimed to investigate the incidence of HCV infection in the general population of district Swat and find the associated risk factors with them. A total of 500 blood samples $(n=500)$ were collected randomly from the general population of the Swat region from November 2016 to June 2017. The blood samples were screened by immune chromatographic (ICT) method to analyze $\mathrm{HCV}$ antibodies. The overall incidence of $\mathrm{HCV}$ was $11.4 \%$ in the studied population. The incidence of $\mathrm{HCV}$ infection was similar in male and female patients $(11.8 \%$ vs. $10.9 \%$, $\mathrm{X} 2=0.27, O R=0.83 ; P$-value 0.37$)$. Young people were significantly more infected than those aged one $(16.9 \%$ vs. $9.8 \%, \mathrm{X} 2=, O R=4, P$ value $>0.05)$. Patients with a blood transfusion history were also more infected than others $(24.1 \%$ vs. $10.7, \mathrm{X} 2=4.9 \mathrm{OR}=3.9 \mathrm{P}$ value=0.03). Our findings concluded that there was a high incidence rate of $\mathrm{HCV}$ infection in the Swat region. Young people and patients were having a history of blood transfusion more infected. This study recommends molecular detection and HCV genotyping in the region.

Keywords: Epidemiology; HCV; Hepatitis; Incidence; Population

\section{Introduction}

Hepatitis $\mathrm{C}$ virus (HCV) is a blood-borne pathogen and a significant global health concern [1]. Following the acquisition of the virus, acute $\mathrm{HCV}$ infection can progress to chronic diseases [2], which is associated with several morbidities, such as liver cirrhosis and cancer [3], which is a tremendous health 
challenges in the world. Approximately 200 million individuals are infected by $\mathrm{HCV}$, which constitutes about $3.3 \%$ of the world population [4]. Among the 3.3\%, the 2 million cases of HCV were reported in Japan, 2.7 million were in the United States, 5 million were in Europe, and about 10 million in Pakistan [5]. Worldwide, Pakistan has the second largest number of HCV infections. The ongoing transmission of HCV appears common, according to a cohort study (a prospective study) and a case-control study (a retrospective study) of patients with acute diseases (or infections), risk factors related to infections include blood transfusion and blood transfusion, and solid organ transplantation from infected donors. Injecting drugs, unsafe therapeutic injections, occupational blood contact (mainly contaminated needle sticks), an infected mother's birth, sex with an infected partner, and sex with multiple partners $[6,7]$. The most important is the blood transfusions of unscreened donors, injected drugs, and unsafe therapeutic injections. However, the degree of influence of these risk factors on HCV transmission varies in time and geography.

World Health Organization (WHO) has been set to eliminate HCV infection as a global health concern by $2030[8,9]$. To achieve the WHO targets for elimination entails an indepth and analytical characterization of $\mathrm{HCV}$ epidemiology in Pakistan, both at the national and regional levels, to develop cost-effective and targeted prevention and treatment interventions. However, up to yet, only one nationally representative population-based survey has been conducted in Pakistan, and over a decade ago [10].

Thus, although the global epidemiological study of hepatitis A and B has been well established, little data is available about HCV in some regions of the world, predominantly in Pakistan. In Pakistan, where there has been an ongoing high risk for decades, the high magnitude of the current burden of $\mathrm{HCV}$ disease is predicted to continue. Thus, the present study will determine HCV incidence in the northern area of Pakistan in district Swat and HCV infection-related risk factors. Materials and Methods Area of sample collection

Five hundred blood samples were collected from the randomly selected patients of 7 different Tehsils of district Swat, Pakistan, between November 2016 to June 2017: Tehsil Kabal, Tehsil Matta, Tehsil Khwaza Khela, Tehsil Barikot, Tehsil Babuzai, Tehsil Charbagh, and Tehsil Bahrain. The total number of samples collected from each tehsil was 50, 36, 94,59,76,53, and 133, respectively.

\section{Inclusion exclusion criteria of the patients} Both males, female's patients and married, unmarried from the age from 16 to 70 years were selected. Only patients from the Swat region were selected. Patients belonging to the other areas or with known HCV infection were excluded from the current study. Those patients who refused to provide their consent were also excluded.

\section{Basic parameters of selected patients}

The data were categorized into groups based on age, gender, married/unmarried status, foreign visits, blood transfusion, barbershop shave, surgery, and dental record.

\section{History of infected patients}

All essential information about the patient's history was recorded by filling a designed questionnaire.

\section{Sample collection}

Before sampling, written consent was taken from each participant. A sterile disposable syringe and needles were used to collect $3 \mathrm{ml}$ of blood from each individual. The blood was then sharply transferred to an ethylene diamine tetra-acetic acid (EDTA) tube containing a proper volume of the anticoagulant. The tubes were labeled with the patient's name, number, and date and shifted to the Biotechnology and 
Microbiology lab Center. The blood was centrifuged at $3000 \mathrm{rpm}$ for 4 minutes. Plasma from each tube was poured into Eppendorf tubes, labeled, and stored in the deep freezer until further experiments.

Screening of patient's plasma for $\mathrm{HCV}$ antibodies by ICT method

The presence of antibodies to $\mathrm{HCV}$ in the blood samples of individuals was tested by the quick method known as HCV rapid test strip. The instructions for carrying out this procedure were taken out from the manufacturer. Among the various other ways, this method is less expensive, fast. It is not laborious in detecting and measuring the antiHCV antibodies in the blood, plasma, and serum of humans. This small strip is coating the membrane of the strip with the antigen of $\mathrm{HCV}$ (test line region). The membrane was also coated with protein particles. During the detection of antibodies in a mixture, the mixture's components react with protein A to start the upward movement by capillary action over the membrane, react with the recombinant $\mathrm{HCV}$ antigen, and react between the recombinant antigen and the mixture; a colored line is created. If a colored line was produced, that was an indication of $\mathrm{HCV}$ infection (positive); on the other hand, there was no colored line in the test region on the membrane, which was a clear indication of the absence of HCV (negative) in the sample. For the colored line to be formed in the control line region, a proper amount of the samples must be loaded onto the membrane, which would lead to the excellent absorbance of samples by the membrane the test as follows. The ICT device was brought to room temperature. One drop $(50 \mu l)$ of plasma was added to the sample well, and an equal volume of diluents was added and incubated at room temperature for ten minutes. The device was observed for red or pink lines on positive control, negative control, and test line. The test was considered invalid if a red line appeared on negative control or no line on positive control.

Statistical analysis

Statistical Package for Social Science (SPSS) 16 and Graph Paid Prism 5 were used for the data interpretation and statistical summary. All of the variables' outcomes were expressed as rates (\%). Fisher's exact and Chi-Square tests were used to determine a positive relationship between the categorical variables. The information was available in the form of mean values or the number of patients. Significant was described as a $P$ value of less than 0.05

\section{Results}

\section{Basic parameters of selected patients}

Age-wise, 388 participants were <40, while 112 were $>40$. Gender-wise, 381 were males, and 119 were females, 376 were married, and 124 were unmarried, 59 had traveled abroad, and 441 had no travel history, 29 had a blood transfusion, and 471 had no blood transfusion. There were 380 barber shaving participants and 120 non-barber shaving participants. While 92 participants underwent surgery, 408 did not. Also, 218 had a tooth extraction, while 282 had no history of dental extraction (Table 1).

Immuno-chromatographic test results for the presence of or absence of $\mathrm{HCV}$ antibodies

The Immuno-chromatographic test was used to determine the presence or absence of HCV antibodies. The total number of negative samples among the 500 samples was 443 (88.6\%), while the number of positive samples was 57 (11.4\%), showing the overall incidence rate in this study (Fig. 1). 
Table 1. Basic parameters of selected patients

\begin{tabular}{|c|c|c|c|}
\hline Parameters & Sub-categories & (Frequency) & Percentage \\
\hline \multirow{2}{*}{ Age } & Less than 40 & 388 & $77.6 \%$ \\
\cline { 2 - 4 } & More than 40 & 112 & $22.4 \%$ \\
\hline \multirow{2}{*}{ Gender } & Male & 381 & $76.2 \%$ \\
\cline { 2 - 4 } & Female & 119 & $23.8 \%$ \\
\hline \multirow{2}{*}{ Marital Status } & Married & 376 & $75.2 \%$ \\
\cline { 2 - 4 } & Unmarried & 124 & $24.8 \%$ \\
\hline \multirow{2}{*}{ Foreign Visit } & Visited & 59 & $11.8 \%$ \\
\cline { 2 - 4 } & Not visited & 441 & $88.2 \%$ \\
\hline \multirow{2}{*}{ Blood Transfusion } & Yes & 29 & $5.8 \%$ \\
\cline { 2 - 4 } & No & 471 & $94.2 \%$ \\
\hline \multirow{2}{*}{ Barber shaved } & Yes & 380 & $76 \%$ \\
\cline { 2 - 4 } & No & 120 & $24 \%$ \\
\hline \multirow{2}{*}{ Surgery } & Yes & 92 & $18.4 \%$ \\
\cline { 2 - 4 } & No & 408 & $81.6 \%$ \\
\hline \multirow{2}{*}{ Dental Extraction } & Yes & 218 & $43.6 \%$ \\
\cline { 2 - 4 } & No & 282 & $56.4 \%$ \\
\hline
\end{tabular}

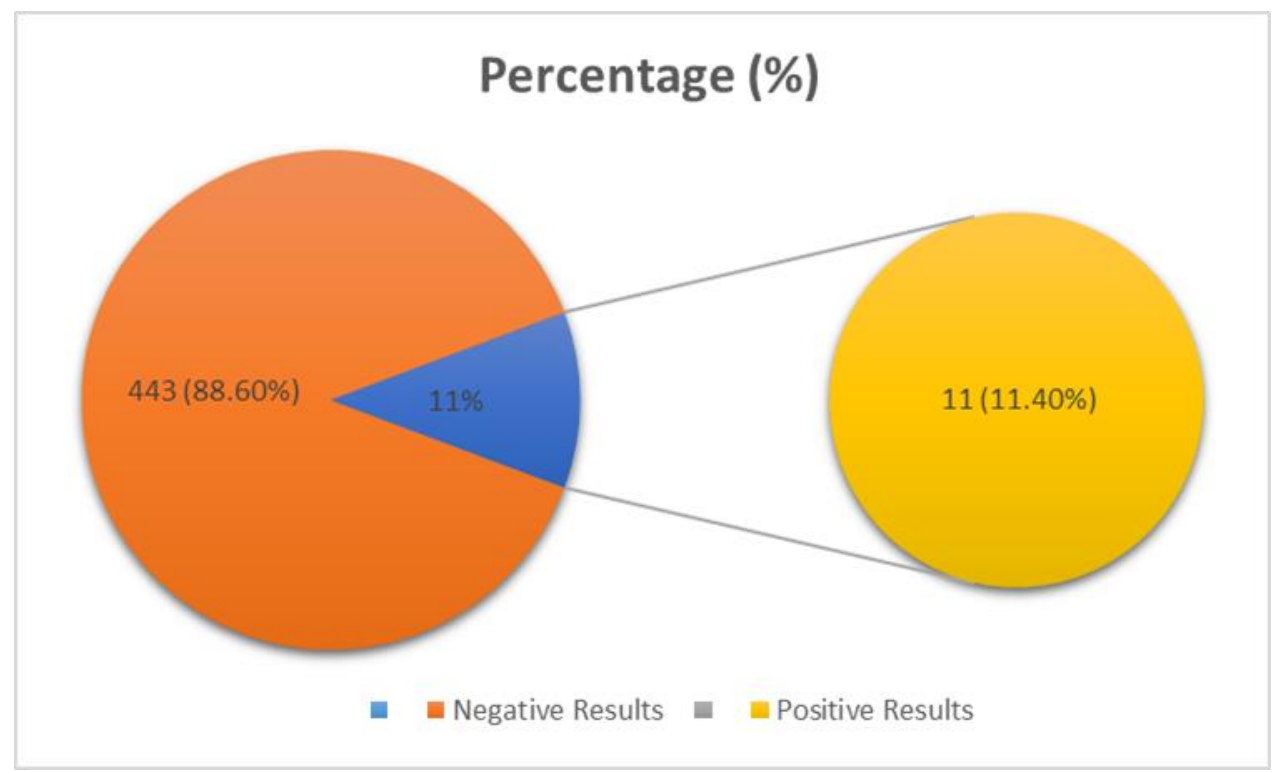

\section{Figure 1. Overall incidence of $\mathrm{HCV}$ infection in Swat region}

\section{Association of test result with different age groups}

The ICT test was conducted for positive and negative HCV antibodies in serum samples. The number of positive and negative cases in the individual of age <40 were 19 and 93, respectively. The number of positive and negative cases in individuals above 40 was 38 and 350, respectively. The total positive and negative cases in both groups were 112 and 388. The incidence rate was higher in the age group of $<40(16.9 \%)$ as compared to the incidence rate in the age group of $>40(9.8 \%)$, and the difference was the significant difference was observed in young age, $P$ value $<0.05, \mathrm{X} 2=4.4, \mathrm{OR}=4$ (Table 2). 
The association between chronic hepatitis $C$ infection and gender

There were 381 male participants in total, with $45(78.9 \%)$ being positive and 336 (75.8\%) being negative. While there were 119 female participants, $12(21.1 \%)$ were positive, and 107 (24.2\%) were negative. The total positive male and female cases were 45 (78.9\%) and $12(12 \%)$, accordingly (21.1\%). Whereas the overall number of negative cases in both genders was $336(75.8 \%)$ and $107(24.2 \%)$, respectively. $\{100-75.8=24.2\}$ (Table 3).
Association between $\mathrm{HCV}$ infection and blood transfusion

HCV positive patients were 57 (23.8\%), and $443(76.2 \%)$ were negative. Among the 57 (23.8\%) HCV-positive patients, 7(25\%) have a blood transfusion record, and 50 (11\%) have no record of blood transfusion. Of the $443(76.2 \%) \mathrm{HCV}$ negative patient the 22 $(75 \%)$ has a record of blood transfusion, and the patient with no blood transfusion history was $421(89 \%)$. There was a statistically significant difference $(P$-value $=0.03)$ (Table 4).

Table 2. Association of tests results with age groups

\begin{tabular}{|c|c|c|c|c|c|}
\hline Age & <40 years & >40 years & Chi-Square & OR & P-Value \\
\cline { 1 - 3 } Negative & $93(83.1 \%)$ & $350(90.2 \%)$ & & & \multirow{2}{*}{4.4} \\
\cline { 1 - 3 } Positive & $19(16.9 \%)$ & $38(9.8 \%)$ & 4 & 0.03 \\
\hline Total & $112(22.4 \%)$ & $388(77.6 \%)$ & & & \\
\hline
\end{tabular}

Table 3. The association between chronic hepatitis $\mathbf{C}$ infection and gender

\begin{tabular}{|c|c|c|c|c|c|}
\hline ICT Results & \multicolumn{2}{|c|}{ Gender } & Chi-Square & OR & P-Value \\
\hline & Male & Female & & & \\
\cline { 1 - 3 } Positive & $45(11.8 \%)$ & $12(10.9 \%)$ & \multirow{2}{*}{0.27} & 0.83 & 0.37 \\
\cline { 1 - 3 } Negative & $336(88.1 \%)$ & $107(89.9 \%)$ & & & \\
\hline Total & $381(76.2 \%)$ & $119(23.8 \%)$ & & & \\
\hline
\end{tabular}

Table 4. The association between HCV infection and blood transfusion

\begin{tabular}{|c|c|c|c|c|c|}
\hline \multirow{2}{*}{ Blood Transfusion } & \multicolumn{2}{|c|}{ HCV Infection } & Chi-Square & P-Value & OR \\
\cline { 2 - 3 } & Yes No & \multirow{2}{*}{4.9} & \multirow{2}{*}{0.03} & \multirow{2}{*}{3.9} \\
\hline Positive & $7(24.1 \%)$ & $50(10.7 \%)$ & & \\
\hline Negative & $22(75.9 \%)$ & $421(89.3 \%)$ & & \\
\hline Total & $29(5.8 \%)$ & $471(94.2 \%)$ & & \\
\hline
\end{tabular}

\section{Discussion}

After detailed deliberation in this study, we found that males were more infected with HCV than females. Similar results were reported by Ayano et al. (2018). They found that male patients were more infected than female patients; however, the incidence rate in our study is $11.8 \%$ compared to $9.16 \%$ reported by them [11]. Our research found that the infection rate was higher in females at $10.9 \%$ than the infection rate at $5.43 \%$ reported by Ayano et al. [11]. Our findings elaborate a higher percentage in males while lower in females. In comparison, our results vary with the previous findings as a higher percentage in females and lower in males, i.e., 20.36 in females and 15.20 in males [12]. The difference in results was due to the difference in sample size. Our findings preclude that $16.9 \%$ of patients with age less than 40 were infected with $\mathrm{HCV}$. A low margin of incidence was found in the previous results reported by Niu et al. [13] they found an incidence rate of $0.93 \%$ [13]. In the present 
study, we investigated the infection rate of $9.8 \%$ in patients of age $>40$. However, the rate of infection found in our study is less than their infection rate, which was $25.85 \%$. In this study, we found that the infection rate of HCV was high in young people. So our results are in disagreement with Niu et al. [13], who reported that the HCV infection rate increased with age above 40 years [14]. In the present study, we found $25 \%$ (7/29) $\mathrm{HCV}$ infection in patients transfused with blood, while in those who were not transfused, it was $11 \% \quad(50 / 471)$. A significantly higher infection rate was investigated in patients with blood transfusion ( $p$ value $=0.03$ ). It can be concluded that unscreened blood for transfusion had a role as a risk of $\mathrm{HCV}$ infection. Similar results were also reported by Niu et al. [13]. They described a higher incidence of hepatitis in blood transfused individuals as compared to a patient with surgery.

\section{Conclusion}

Based on our results, we may conclude that $\mathrm{HCV}$ is still a health problem, especially in District Swat, and unscreened blood transfusion may be a risk factor for $\mathrm{HCV}$ infection. It was the point to consider that aged people were more susceptible to disease. Thus, there was an urgent need for public awareness about $\mathrm{HCV}$ transmission and prevention. The study suggests molecular detection and genotyping of these patients.

\section{Authors' contributions}

Conceived and designed the experiments: $\mathrm{N}$ Zaman \& F Akbar, Performed the experiments: Z Khan, S Iqbal \& IA Mian, Analyzed the data: Z Khan, N Zaman, RT Mahmood \& G Rahim, Contributed materials/ analysis/ tools: N Zaman, F Akbar \& A Khan, Wrote the paper: Z Khan, N Zaman, A Khan \& D Ualiyeva.

\section{References}

1. Piroth L, Rabaud, C, Rey D, Schmit JL, Chirouze C, Beck-Wirth G \& Bani-Sadr F (2016). Hepatitis C: the path towards effective universal therapy. The Lancet 388(10049): 1051-1052

2. Chen SL, \& Morgan TR (2006). The natural history of hepatitis $\mathrm{C}$ virus (HCV) infection. Inter J of Med Sci 3(2): 47.

3. Bouvard V, Baan R, Straif K, Grosse Y, Secretan B, El Ghissassi F \& Cogliano V (2009). A review of human carcinogens-Part B: biological agents. The Lancet Oncol 10(4): 321-322.

4. Khan Z (2017). Incidence of HCV in general population of District Swat, Pakistan. J of Antivirals \& Antiretrovirals 09(03).

5. Hamid S, Umar M, Alam A, Siddiqui A, Qureshi H \& Butt J (2004). PSG consensus statement on management of hepatitis $\mathrm{C}$ virus infection--2003. JPMA. The J of the Pak Med Assoc 54(3): 146150.

6. CfDC CDC (1998). Recommendations for prevention and control of hepatitis $\mathrm{C}$ virus (HCV) infection and $\mathrm{HCV}$-related chronic disease. Morbidity Mortality Weekly Rep 47: 1-39.

7. Wedemeyer H, Dore GJ \& Ward JW (2015). Estimates on HCV disease burden worldwide-filling the gaps. $J$ of Viral Hepa 22: 1-5.

8. Mohamoud YA, Riome S \& Abu-Raddad LJ (2016). Epidemiology of hepatitis C virus in the Arabian Gulf countries: Systematic review and meta-analysis of prevalence. Inter J of Infec Dis 46: 116125.

9. World Health Organization. (2016). Combating hepatitis $B$ and $C$ to reach elimination by 2030: advocacy brief (No. WHO/HIV/2016.04). World Health Organization.

10. Xiao X, Wu ZC \& Chou KC (2011). A multi-label classifier for predicting the 
subcellular localization of gram-negative bacterial proteins with both single and multiple sites. PloS One 6(6): e20592.

11. Ayano G, Tulu M, Haile K, Assefa D, Habtamu Y, Araya G \& Yohannis Z (2018). A systematic review and metaanalysis of gender difference in epidemiology of HIV, hepatitis B, and hepatitis $\mathrm{C}$ infections in people with severe mental illness. Annals of general Psychiatry 17(1): 1-14.

12. Esmaeili A, Mirzazadeh A, Carter GM, Esmaeili A, Hajarizadeh B, Sacks HS \& Page KA (2017). Higher incidence of $\mathrm{HCV}$ in females compared to males who inject drugs: a systematic review and meta-analysis. J of Viral Hepa 24(2): 117-127.

13. Niu Z, Zhang P \& Tong Y (2016). Age and gender distribution of Hepatitis $C$ virus prevalence and genotypes of individuals of physical examination in WuHan,

Central

China. SpringerPlus 5(1): 1557.

14. Tunio SA, Bano S, Laghari ZA, Ali W, Shamim H \& Afreen U (2013). Seroprevalence of Hepatitis-B, and C among blood donors in Hyderabad, Pakistan. Gomal J of Med Sci 11(2): 220223. 